\title{
Dual Arterial Access for Stenting of Aortic Coarctation in Patients with Near-Total Descending Aortic Interruption
}

Tahir Hamid · Syed Ibrahim Jamallulail · Bernard Clarke •

Vaikom S. Mahadevan

To view enhanced content go to www.cardiologytherapy-open.com

Received: July 31, 2015 / Published online: September 19, 2015

(c) The Author(s) 2015. This article is published with open access at Springerlink.com

\section{ABSTRACT}

Endovascular stenting is a recognized treatment strategy for the treatment of coarctation of aorta (COA) in adults. The aortic coarctation is usually crossed retrogradely from the descending aorta via the femoral approach. We report three patients who had near-total descending aortic interruption and underwent successful stenting of severe COA using a combined radial/brachial and femoral approach due to difficulty in crossing the lesion retrogradely via a femoral approach. There were no procedural complications and no adverse events during 6 months of follow-up.

Keywords: Coarctation of aorta; Descending aortic interruption; Radial artery

\section{INTRODUCTION}

Coarctation of aorta (COA) represents $5-10 \%$ of all congenital cardiac lesions [1]. We present

T. Hamid · S. I. Jamallulail · B. Clarke ·

V. S. Mahadevan ( $\square)$

Manchester Royal Infirmary, Manchester, UK

e-mail: vaikom.mahadevan@ucsf.edu;

vsmkm@yahoo.co.uk three patients (see Table 1) with near-total descending aortic occlusion where it was not possible to cross the COA lesion via the retrograde femoral approach. Informed consent was obtained from all three patients before they were included in the study.

\section{CASE 1}

A 63-year-old male presented with an episode of palpitations and chest pains. Cardiac catheterization via the right radial artery (RRA) revealed nonobstructive coronary artery disease. A computed tomography (CT) scan of the aorta confirmed a very severe aortic coarctation at the level of the isthmus with near-total descending aortic occlusion.

\section{Procedure}

A 6 French (F) sheath was inserted into the right femoral artery (RFA) and upsized to an 8 F sheath. The right radial artery was impalpable so we used the right brachial approach and a $5 \mathrm{~F}$ sheath was inserted. A $5 \mathrm{~F}$ pigtail catheter was deployed at the aortic arch. A Gensini MPB $3{ }^{\circledR}$ catheter was used via the femoral route. There was a large aneurysmal area beneath the coarctation and it was not 
Table 1 Patient demographics and procedural details

\begin{tabular}{llll}
\hline & Case 1 & Case 2 & Case 3 \\
\hline Transverse arch diameter $(\mathrm{mm})$ & 23 & 16 & 11 \\
Age (years) & 63 & 23 & 21 \\
Past medical history & Hypertension & Hypertension & Hypertension \\
& & Bicuspid aortic & Bicuspid aortic valve \\
& & valve & \\
Left ventricular $(\mathrm{LV})$ function on trans-thoracic & Good & Good & Moderate \\
echocardiogram & & & impairment \\
Minimal luminal diameter of CoA (mm) & 5 & 3 & 1 \\
Post-CoA diameter (mm) & 49 & 38 & 20 \\
Gradient pre-procedure (mmHg) & 46 & 40 & 40 \\
Gradient post-procedure (mmHg) & 3 & 10 & 12 \\
\hline
\end{tabular}

possible to cross the coarctation from the femoral end, despite multiple attempts. In view of this, we used a JR $4{ }^{\circledR}$ (Cordis, Fremont, CA, USA) diagnostic catheter from the right brachial artery and the COA was crossed with a Terumo ${ }^{\circledR}$ wire. The JR4 guide was positioned and maneuvered over the wire into the descending aorta. This was exchanged for an Amplatz Super stiff wire $0.35^{\circledR}$ (Boston Scientific, MA, USA) exchange length wire. A 6 Fr EnSnare kit (ev3 Inc.) was deployed through the femoral arterial approach and the Amplatzer Super Stiff ${ }^{\circledR}$ wire was snared from the iliac into the RFA groin site. Following this, the wire was carefully exteriorized via the femoral sheath. The COA lesion was then successfully stented using an uncovered Cheatham Platinum $(\mathrm{CP})^{\mathrm{TM}}$ stent $\left(\mathrm{NuMED}^{\mathrm{TM}}\right.$, Hopkinton, NY, USA) with a 16-mm balloon-in-balloon (BIB) NuMED ${ }^{\mathrm{TM}}$ catheter. The patient remained clinically well during 6 months of follow-up.

\section{CASE 2}

A 23-year-old male with hypertension and a bicuspid aortic valve was diagnosed with severe COA with near-total descending aortic occlusion on CT scan. 24-h ambulatory blood pressure monitoring revealed a reading of $162 / 80 \mathrm{mmHg}$.

\section{Procedure}

A 6 F sheath was inserted into the RFA and RRA. A pigtail catheter was positioned in the ascending aorta (radial route) and a Gensini ${ }^{\circledR}$ catheter was positioned in the descending aorta. It was not possible to cross the coarctation from the femoral end, despite multiple attempts. We then used a $\mathrm{JR} 4^{\circledR}$ diagnostic catheter from the wrist and managed to cross the lesion using a Terumo ${ }^{\circledR}$ wire (Terumo Medical, NJ, USA), which was then exchanged for an Amplatzer Super Stiff ${ }^{\circledR}$ wire. This was then snared via the femoral sheath using an EnSnare kit (ev3 Inc.). A covered $4.5-\mathrm{cm} \mathrm{CP}^{\mathrm{TM}}$ stent $\left(\mathrm{NuMED}^{\mathrm{TM}}\right.$ ) mounted on a $16-\mathrm{mm}$ BIB NuMED $^{\mathrm{TM}}$ catheter was successfully deployed using the femoral approach, and the patient remained well during 5 months of follow-up.

\section{CASE 3}

A 21-year-old female patient with hypertension presented with episodes of chest pain and 
progressive dyspnea. An echocardiogram revealed a bicuspid aortic valve with significant aortic regurgitation and significantly impaired LV systolic function. A CT aortogram and cardiac MR scan revealed a severe discrete coarctation with near-total descending aortic occlusion in the distal arch with marked collateral vessels (Figs. 1, 2).

\section{Procedure}

A 6 F sheath was inserted into the RRA and a $6 \mathrm{~F}$ sheath into the RFA, which was upsized to an 8 F sheath. Using a JR $4^{\circledR}$ diagnostic catheter and a radial approach, we managed to cross the coarctation using a Terumo $^{\circledR}$ wire into the descending aorta. This was exchanged for an Amplatz Super Stiff ${ }^{\circledR} 260-\mathrm{cm}$ wire. This wire was
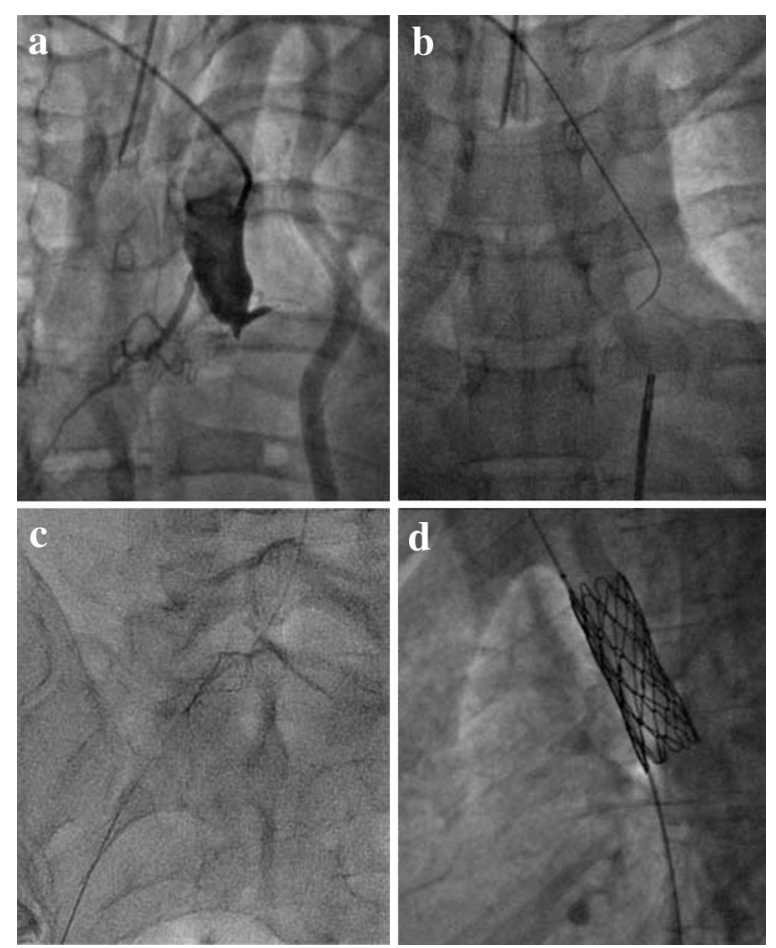

Fig. 1 Case 3. a Aortography of the arch showing the near-complete obstruction. b Crossing the lesion with a Terumo ${ }^{\circledR}$ wire. c Amplatz Super Stiff ${ }^{\circledR}$ wire snared via the femoral sheath using an EnSnare (ev3 Inc.) snare. d Aortogram showing the well-deployed COA stent
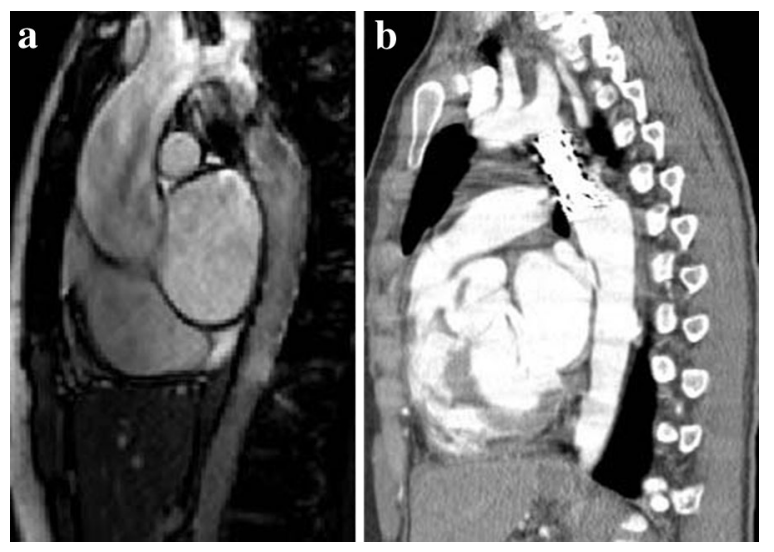

Fig. 2 Case 3. a Cardiac MRI showing severe CoA. b CT scan showing the deployed COA stent

then snared via the femoral sheath using an EnSnare kit (ev3 Inc.). Next, we successfully deployed a covered $4.5-\mathrm{cm} \quad \mathrm{CP}^{\mathrm{TM}}$ stent $\left(\mathrm{NuMED}^{\mathrm{TM}}\right)$ using a 14-mm BIB NuMED ${ }^{\mathrm{TM}}$ catheter. She was well at the 6-week clinical follow-up and was referred to the cardiac surgeons for surgical aortic valve replacement.

\section{DISCUSSION}

Coarctation of aorta can present with a complex anatomical spectrum from moderate stenosis to near-total descending aortic occlusion. However, in patients with near-total descending aortic occlusion, crossing the coarctation retrogradely (femoral) can be difficult. In the routine COA stenting procedure, vascular access is achieved from the femoral artery in all patients. Further arterial access is achieved using the right radial artery in all patients to monitor simultaneous aortic pressure across the COA [2]. The COA is crossed retrograde via a femoral approach to deploy the COA stent. In the above patients, it would not have been possible to be certain that the wire had crossed the lesion via the true aortic lumen if the retrograde approach had been used, thus significantly increasing the risk for aortic perforations. Moreover, the wire can enter small 
collateral branches and could lead to potentially fatal complications if intervention is proceeded with in a collateral vessel. Using the radial/ brachial approach in the type of lesions mentioned in this series results in safe crossing of the aortic coarctation antegradely. This approach can potentially avoid the need for COA repair surgery, which has been associated with serious complications [3, 4]. Similarly, complications can potentially arise in patients with an aneurysmal anatomy; indeed, Alcibar et al. [5] reported that a patient in whom a radial-femoral approach was adopted died during the index procedure secondary to aneurysmal rupture into the esophagus post CoA stenting. We used covered stents in two of our patients. Currently, patients usually undergo covered stent implantation, which may decrease but not eliminate the risk of aortic perforation [6], However there is a risk of occlusion of the left subclavian artery or occlusion of other branches of the aorta [7] with covered stents.

\section{CONCLUSION}

Successful COA stenting can be achieved with the use of dual arterial access in patients with severe coarctation lesions with total or near-total descending aortic occlusion, thus obviating the need for open-surgical repair.

\section{ACKNOWLEDGMENTS}

No funding or sponsorship was received for this study or the publication of this article. All named authors meet the International Committee of Medical Journal Editors (ICMJE) criteria for authorship for this manuscript, take responsibility for the integrity of the work as a whole, and have given final approval for this version to be published.
Conflict of interest. Tahir Hamid, Syed Ibrahim Jamallulail, Bernard Clarke, and Vaikom S. Mahadevan declare no conflict of interests.

\section{Compliance with ethics} guidelines. Informed consent was obtained from all patients before they were included in the study.

Open Access. This article is distributed under the terms of the Creative Commons Attribution-NonCommercial 4.0 International License (http://creativecommons.org/licenses/ by-nc/4.0/), which permits any noncommercial use, distribution, and reproduction in any medium, provided you give appropriate credit to the original author(s) and the source, provide a link to the Creative Commons license, and indicate if changes were made.

\section{REFERENCES}

1. Kaemmerer H. Aortic coarctation and interrupted aortic arch. In: Gatzoulis MA, Webb DG, Daubeney PEF, editors. Diagnosis and management of adult congenital heart disease. New York: Churchill Livingstone; 2003. p. 254.

2. Dehghani P, Collins N, Benson L, Horlick E. Role of routine radial artery access during aortic coarctation interventions. Catheter Cardiovasc Interv. 2007;70(4):622-3.

3. Varejka P, Lubanda JC, Prochazka P, Heller S, Beran S, Dostal $\mathrm{O}$, et al. Late complication of surgical repair of aortic coarctation: ruptured pseudoaneurysm of the aorta treated by thoracic endovascular aortic repair. J Mal Vasc. 2010;35:189-93.

4. Keen G. Spinal cord damage and operations for coarctation of the aorta: aetiology, practice, and prospects. Thorax. 1987;42:11-8.

5. Alcibar J, Blanco R, Fernandez L, Arriola J, Garcia K, Peña N, et al. Elective implantation of covered stents for coarctation and recoarctation in adolescents and adults. Rev Esp Cardiol. 2013;66(6):443-9. 
6. Collins N, Mahadevan V, Horlick E. Aortic rupture following a covered stent for coarctation: delayed recognition. Catheter Cardiovasc Interv. 2006;68:653-5.

7. Forbes TJ, Garekar S, Amin Z, Zahn EM, Nykanen D, Moore P, Qureshi SA, Cheatham JP, Ebeid MR, Hijazi ZM, Sandhu S, Hagler DJ, Sievert H, Fagan TE, Ringewald J, Du W, Tang L, Wax DF, Rhodes J,
Johnston TA, Jones TK, Turner DR, Pedra CA, Hellenbrand WE, Congenital Cardiovascular Interventional Study Consortium (CCISC). Procedural results and acute complications in stenting native and recurrent coarctation of the aorta in patients over 4 years of age: a multi-institutional study. Catheter Cardiovasc Interv 2007;70:276-85. 